\title{
Psychosocial Risk Factors for Transitions Into Housing Instability Among Women Veterans
}

\section{Ellen Mulcaby, PhD, Dorota Szymkowiak, PhD, and Ann Elizabeth Montgomery, PhD}

Introduction: Preventing and ending homelessness for women veterans, a priority of the Department of Veterans Affairs (VA), can be aided by identifying factors that increase their risk for housing instability.

Methods: This study relied on data from the Veterans Health Administration's universal screen for housing instability from Fiscal Year 2013 to 2016, and administrative data from electronic medical records. Using logistic regression, we compared 2 groups of women veterans: those who consistently had stable housing and those who transitioned to unstable housing after a period of housing stability.

Results: We found that a history of military sexual trauma, lack of access to VA benefits and other financial resources, and single or divorced marital status were significant risk factors for women veterans' housing instability. These findings are consistent with an existing theoretical model of housing instability and homelessness among women veterans, which highlights the importance of traumatic and adverse events and isolation as risk factors.

Conclusions: These risk factors and their effect on women veterans' housing instability can be mitigated by new and increased supportive interventions, targeted to those at highest risk. ( $\mathrm{J}$ Am Board Fam Med 2021;34:387-391.)

Keywords: Health Policy, Homeless Persons, Housing, Logistic Models, Mental Health, Risk Factors, Sexual Trauma, Veterans Health Administration

The population of women veterans is increasing as more women enroll in military service. ${ }^{1,2}$ Women veterans are disproportionately impacted by homelessness; at least 2 studies have found that women veterans have a higher risk for homelessness than female nonveterans. ${ }^{3,4}$ Also, studies have found women veterans to have a greater risk of homelessness than their male counterparts, ${ }^{5,6}$ and particular subgroups of women veterans are more likely to use

This article was externally peer reviewed.

Submitted 30 June 2020; revised 1 December 2020; accepted 29 December 2020.

From Department of Behavioral and Social Science, University of Sciences (EM); National Center on Homelessness among Veterans (DS); National Center on Homelessness among Veterans, Birmingham VA Medical Center, and University of Alabama at Birmingham School of Public Health, Birmingham, AL (AEM).

Conflict of interest: We have no conflicts of interest to disclose.

Funding: The authors received no financial support for the research, authorship, and/or publication of this article.

Corresponding author: Ellen Mulcahy, PhD, University of the Sciences, Department of Behavioral and Social Science, 600 South 43rd Street, Philadelphia, PA 19104-4495 (Email: emulcahy@usciences.edu). the Veterans Health Administration's (VHA) Homeless Programs than male veterans. ${ }^{7}$ Differences in prevalence, characteristics, and patterns of homelessness between men and women veterans suggest that women veterans may have distinct risks for and pathways into homelessness. ${ }^{8-10}$

Risk factors for homelessness for women veterans include nonwhite race, ${ }^{11,4}$ single or divorced marital status, ${ }^{12,13}$ unemployment and disability, ${ }^{13}$ mental health conditions, ${ }^{12-16}$ traumatic brain injury, ${ }^{13,16,17}$ substance use disorder, ${ }^{14,15,17}$ and indicators of experiences of trauma, such as post-traumatic stress disorder (PTSD) and history of military sexual trauma (MST), defined by Veterans Affairs (VA) as "sexual assault or repeated, threatening sexual harassment that a veteran experienced during his or her military service." ${ }^{12,13,16,18}$ Previous research has not revealed substantially different risk factors for homelessness for men and women; however, some risk factors such as MST disproportionately affect women. ${ }^{18}$

Research has inadequately explored factors that may explain women veterans' transitions into housing instability. Given women veterans' unique needs—-for 
example, they are more likely to experience shorter periods of homelessness, ${ }^{7}$ are often homeless with children, ${ }^{5,19}$ and more frequently have needs related to mental health rather than substance use $\mathrm{s}^{5,6,7,20}$-it is important to understand intervention points to prevent transitions from stable to unstable housing. Preventing women's transitions into homelessness will likely reduce their experience of poor health outcomes (eg, premature mortality, ${ }^{21}$ higher rates of comorbid conditions), ${ }^{22}$ which are often associated with housing instability. This is particularly relevant as the US Department of Veterans Affairs provides resources through Supportive Services for Veteran Families (SSVF) and other programs to prevent and end homelessness among veterans.

The objective of this study is to investigate risk factors for women veterans' transitions into housing instability to identify interventions to prevent housing instability.

\section{Methods}

We collected administrative data from electronic medical records for 194,330 women veterans who responded to the VHA's universal screen for housing instability $^{23} 3$ or more times during Fiscal Year 2013 to 2016 and whose first 3 responses indicated either consistently stable housing (ie, 3 consecutive negative screens) or a transition to housing instability after a period of stable housing (ie, 2 consecutive negative screens followed by a positive screen). This screen was administered nationally during the study period to veterans accessing primary care through VHA who were not already engaged with VHA Homeless Programs or receiving long-term or palliative care. ${ }^{21} \mathrm{We}$ conducted a logistic regression identifying correlates of transition to unstable housing; correlates of interest included marital status; discharge status from the military; military service during Operations Enduring Freedom, Iraqi Freedom or New Dawn (OEF/OIF/ $\mathrm{OND}$ ); service-connected disability; combat exposure; experience of MST; and diagnosis of a chronic medical, mental health, or substance use condition. We controlled for race and age in the model.

\section{Results}

Table 1 provides descriptive statistics for the age and race of the two groups. Mean age and age distribution were similar across groups although there were small differences in age distribution. The racial makeup of the two study groups differed, with non-
Table 1. Demographic Characteristics of the Study Population ( $\mathrm{N}=194$ 330)

\begin{tabular}{lcc}
\hline & $\begin{array}{c}\text { No Housing } \\
\text { Instability } \\
(\mathrm{n}=192513) \\
\%\end{array}$ & $\begin{array}{c}\text { Transition into } \\
\text { Housing Instability } \\
(\mathrm{n}=1817) \\
\%\end{array}$ \\
\hline Age, years & & \\
18 to 34 & 18.0 & 15.9 \\
35 to 44 & 17 & 18.1 \\
45 to 54 & 26.9 & 30.0 \\
55 to 64 & 24.9 & 28.0 \\
$65+$ & 12.3 & 8.0 \\
Mean $(S D)$ & $49.6(14.2)$ & $49.0(12.1)$ \\
Race/ethnicity & & \\
Non-Hispanic White & 61.2 & 50.3 \\
Non-Hispanic Black & 29.0 & 37.8 \\
Hispanic & 6.1 & 6.6 \\
Other & 3.8 & 5.3 \\
\hline
\end{tabular}

SD, standard deviation.

Hispanic white participants making up a larger percent of the stably housed group (61.2) compared with the group that experienced housing instability (50.3) and non-Hispanic Black participants making up a smaller percent of the group that remained stably housed (29.0) compared with the group that experienced housing instability (37.8). In the group that remained stably housed there was also a smaller percent of people whose race was identified as "Other" (3.8) compared with the group that experienced housing instability (5.3). The percent of participants identifying as Hispanic was similar across the two groups (6.1 and 6.6.) (Table 1).

Table 2 compares sociodemographic and clinical characteristics for women veterans who did and did not transition into unstable housing, controlling for age and race. Women veterans who experienced housing instability were more likely to be single (adjusted odds ratio $[\mathrm{aOR}]=2.08,95 \%$ confidence interval $[\mathrm{CI}]$, 1.84 to 2.36 ), divorced ( $\mathrm{aOR}=1.95,95 \% \mathrm{CI}, 1.69$ to 2.25 ), or widowed (aOR 1.40, 95\% CI, 1.07 to 1.82 ) compared with the consistently stably housed group. They were also less likely to be receiving compensation related to a disability incurred during military service $(\mathrm{aOR}=0.75,95 \% \mathrm{CI}, 0.67$ to 0.85$)$ and less likely to have been honorably discharged ( $\mathrm{aOR}=0.63$, 95\% CI, 0.49 to 0.82), although the difference between the 2 groups was small $(96.5 \%$ among those experiencing housing instability compared with $98.1 \%$ among those stably housed). 
Table 2. Correlates in Multiple Regression Model of Transition From Stable to Unstable Housing ( $=194330$ )*

\begin{tabular}{|c|c|c|c|c|c|}
\hline Characteristic & $\begin{array}{l}\text { No Housing Instability } \\
(\mathrm{n}=192513)^{\dagger} \\
\%\end{array}$ & $\begin{array}{c}\text { Transition into Housing } \\
\text { Instability }(\mathrm{n}=1817) \\
\%\end{array}$ & $\mathrm{aOR}$ & $95 \% \mathrm{CI}$ & $P$ Value \\
\hline \multicolumn{6}{|l|}{ Marital status } \\
\hline Married & 35.6 & 19.9 & * & * & * \\
\hline Single & 20.9 & 25.2 & 2.08 & $1.84-2.36$ & $<0.001$ \\
\hline Divorced/separated & 38.0 & 50.9 & 1.95 & $1.69-2.25$ & $<0.001$ \\
\hline Widowed & 5.6 & 4.0 & 1.40 & $1.07-1.82$ & 0.013 \\
\hline \multicolumn{6}{|l|}{ Service-connected disability } \\
\hline $0 \%$ & 33.8 & 32.4 & * & * & * \\
\hline $10 \%$ to $40 \%$ & 19.8 & 22.1 & 1.11 & $0.97-1.27$ & 0.14 \\
\hline $50 \%$ to $100 \%$ & 46.4 & 45.6 & 0.75 & $0.67-0.85$ & $<0.001$ \\
\hline $\begin{array}{l}\text { Operation Enduring } \\
\text { Freedom/Operation Iraqi } \\
\text { Freedom/Operation New } \\
\text { Dawn }\end{array}$ & 15.6 & 16.2 & 1.08 & $0.93-1.26$ & 0.30 \\
\hline \multicolumn{6}{|l|}{ Discharge Status } \\
\hline Non-honorable discharge & 0.1 & 0.4 & * & * & * \\
\hline Honorable discharge & 98.1 & 96.5 & 0.63 & $0.49-0.82$ & $<0.001$ \\
\hline Combat exposure & 6.4 & 7.3 & 0.98 & $0.80-1.19$ & 0.81 \\
\hline Military sexual trauma & 28.6 & 43.4 & 1.57 & $1.42-1.75$ & $<0.001$ \\
\hline Chronic medical condition & 19.3 & 22.6 & 1.03 & $0.91-1.16$ & 0.64 \\
\hline Depression & 22.4 & 39.2 & 1.74 & $1.52-1.99$ & $<0.001$ \\
\hline PTSD & 10.5 & 23.4 & 1.49 & $1.27-1.75$ & $<0.001$ \\
\hline Psychosis & 2.4 & 3.6 & 1.37 & $1.06-1.78$ & 0.016 \\
\hline Suicide/self-harm & 0.8 & 2.1 & 0.93 & $0.64-1.33$ & 0.68 \\
\hline Alcohol use disorder & 1.3 & 4.5 & 1.49 & $1.13-1.98$ & 0.005 \\
\hline Drug use disorder & 1.2 & 4.6 & 1.77 & $1.34-2.35$ & $<0.001$ \\
\hline
\end{tabular}

aOR, adjusted odds ratio; CI, confidence interval; PTSD, post-traumatic stress disorder.

*Reference group.

${ }^{\dagger}$ The analyses controlled for the following variables not included in this table: race (Non-Hispanic black, Non-Hispanic white, Hispanic, Other race), age groups in years (18 to 34,35 to 44,45 to $64,65+$ ), number of weeks between first and last screen for housing instability.

Women veterans who reported transitioning into housing instability were also more likely to have reported MST (aOR=1.57, 95\% CI, 1.42 to 1.75). While chronic medical conditions were not significantly different between the 2 groups, women veterans who transitioned into unstable housing were more likely to have a diagnosis of depression $(\mathrm{aOR}=1.74,95 \% \mathrm{CI}, 1.52$ to 1.99$)$, PTSD (aOR = $1.49,95 \% \mathrm{CI}, 1.27$ to 1.75 ), or psychosis $(\mathrm{aOR}=$ $1.37,95 \%$ CI, 1.06 to 1.78 ), as well as a history of alcohol use disorder $(\mathrm{aOR}=1.49,95 \% \mathrm{CI}, 1.13$ to $1.98)$ or drug use disorder $(\mathrm{aOR}=1.77,95 \% \mathrm{CI}$, 1.32 to 2.35 ). (Table 2).

\section{Discussion}

The findings match a model of homelessness risk among women veterans in which experiences of trauma play a major role in increasing vulnerability to homelessness, enhanced by "contextual factors" such as isolation and lack of resources. ${ }^{15,24}$ Based on a qualitative study of women veterans experiencing homelessness, Hamilton and colleagues ${ }^{15}$ highlighted the important role of trauma and adverse events in the path from military service to homelessness, identifying events and conditions that create and intensify vulnerabilities leading to homelessness. These events act as pivotal points that can alter the life course of women veterans and make an experience of homelessness much more likely.

The risk factor that most elevated women veterans' risk of homelessness in this study was being single or divorced; this finding is consistent with previous research that has shown married status to be a protective factor against homelessness for 
veterans. ${ }^{12,13}$ Being single or divorced may contribute to 2 "contextual factors" that Hamilton and colleagues $^{15}$ found to increase female veterans' cumulative vulnerability to homelessness: lack of resources and a sense of isolation. Marriage may protect veterans from homelessness by increasing their financial and emotional support. Alternate forms of these types of support could be provided programmatically in the form of child care subsidies, emergency financial assistance, and emergency crisis counseling, and could be targeted to women veterans at high risk of housing instability.

Two factors that determine a veteran's ability to receive ongoing financial VA benefits were protective against homelessness. First, the type of military discharge determines veterans' eligibility for multiple types of financial support, including home loan assistance, educational assistance, pension, disability payments, and VHA health services; ${ }^{25}$ an honorable discharge from the military was found to be a significant protective factor against women veterans' transitions into unstable housing. Second, women veterans who had a service-connected disability rating of $50 \%$ to $100 \%$ had lower odds of transitioning into housing instability compared with those without any service-connected disability. This finding suggests the protective role of a consistent financial benefit. In contrast, a service-connected disability of $1 \%$ to $49 \%$ was not protective, suggesting that a lower monthly benefit was insufficient to protect against homelessness. These findings reflect the power of ongoing and stable financial benefits to prevent homelessness. Efforts could occur simultaneously to increase access to financial benefits and increase the utility of these benefits to reduce the risk of housing instability: assistance with application for VA financial benefits for benefits-eligible women veterans and making emergency financial assistance available to those women veterans who are ineligible for regular VA benefits and at risk of housing instability.

Experiences of trauma that occur both within and outside of veterans' military service play a significant role in women veterans' pathways into homelessness. ${ }^{15}$ This study corroborates this finding as an experience of MST (sexual trauma during the period of military service, whether by another military member or someone outside the military) increased women veterans' risk of homelessness by $57 \%$, and diagnosis of PTSD increased the risk by $49 \%$. One hypothesis is that women with such experiences may be less likely to seek assistance in a system that largely serves men. ${ }^{26}$

Findings related to mental health diagnoses and substance use disorders are also consistent with this model of homelessness vulnerability: diagnoses of depression, psychosis, or substance use disorder each significantly increased the odds of women veterans transitioning to unstable housing. Ensuring access to mental health and substance use supports, assistance with application for VA financial benefits, and emergency financial assistance for female veterans reporting histories of trauma could reduce their risk of housing instability.

Several limitations must inform how we apply these findings. First, the study population was limited to women veterans who accessed VHA care within the study period; therefore, the results may not generalize to the broader veteran population. Second, women veterans' transitions from stable to unstable housing were observed within a specific period; instances of housing instability occurring outside of the period were not considered. Third, the correlates included in the model were limited to those available in VHA databases and may not include all relevant variables.

Our findings confirming MST as a risk for homelessness among women veterans suggest that better prevention and response to MST is called for in the active-duty military population, as well as increased mental health supports for veterans to address MST and increased targeting of homelessness prevention programs to veterans with a significant history of trauma and adverse events. Our findings also suggest that programs with a large preventive impact for such veterans would include child-care subsidies, emergency financial assistance, crisis counseling, and assistance with application for VA financial benefits. Preventing women veterans' transitions into housing instability may also protect against other poor health outcomes.

To see this article online, please go to: http://jabfm.org/content/ 34/2/387.full.

\section{References}

1. US Department of Defense, Office of the Deputy Assistant Secretary of Defense for Military Community and Family Policy. Demographics profile of the military community. Available at http:// download.militaryonesource.mil/12038/MOS/Reports/ 2015-Demographics-Report.pdf. Published 2016. Accessed November 29, 2020. 
2. US Department of Defense. Population representation in the military services: appendix table D13. Available at https://www.cna.org/pop-rep/2014/ appendixd/d_13.html. Published 2014. Accessed November 29, 2020.

3. Gamache G, Rosenheck R, Tessler R. Overrepresentation of women veterans among homeless women. Am J Public Health 2003;93:1132-6.

4. Fargo J, Metraux S, Byrne T, et al. Prevalence and risk of homelessness among US veterans. Prev Chronic Dis 2012;9:E45.

5. US Department of Housing and Urban Development and US Department of Veterans Affairs. Veteran Homelessness: A Supplemental Report to the 2010 Annual Homeless Assessment Report to Congress. 2011. Washington, D.C.

6. US Department of Housing and Urban Development and US Department of Veterans Affairs. Veteran Homelessness: A Supplemental Report to the 2009 Annual Homeless Assessment Report to Congress. 2010. Washington, D.C.

7. Blackstock OJ, Haskell SG, Brandt CA, Desai RA. Gender and the use of veterans Health Administration homeless services programs among Iraq/ Afghanistan veterans. Med Care 2012;50:347-52.

8. Tsai J, Kasprow WJ, Kane V, Rosenheck RA. National comparison of literally homeless male and female VA service users: entry characteristics, clinical needs, and service patterns. Women's Health Issues 2014;24:e29-e35.

9. Leda C, Rosenheck R, Gallup P. Mental illness among homeless female veterans. Hospital and Community Psychology 1992;43:1026-8.

10. Tsai J, Rosenheck RA, McGuire JF. Comparison of outcomes of homeless female and male veterans in transitional housing. Community Ment Health J 2012;48:705-10.

11. Montgomery AE, Szymkowiak D, Tsai J. Housing instability and homeless program use among veterans: the intersection of race, sex, and homelessness. Hous Policy Debate 2020;30:396-408.

12. Montgomery AE, Dichter ME, Thomasson AM, Fu X, Roberts CB. Demographic characteristics associated with homelessness and risk among female and male veterans accessing VHA outpatient care. Womens Health Issues 2015;25:42-8.

13. Washington DL, Yano EM, McGuire J, Hines V, Lee M, Gelberg L. Risk factors for homelessness among women veterans. J Health Care Poor Underserved 2010;21:81-91.

14. Hines VA. Homelessness: Women Veterans' Perspective. (Doctoral dissertation). 2009. Retrieved from Proquest Dissertation and Theses.

15. Hamilton AB, Poza I, Washington DL. Homelessness and trauma go hand-in-hand: pathways to homelessness among women veterans. Womens Health Issues 2011;21:S203-S209.

16. Department of Veterans Affairs, Office of the Inspector General. Homeless incidence and risk factors for becoming homeless in veterans. 2012. Washington, DC.

17. Montgomery AE, Dichter ME, Thomasson AM, Roberts CB, Byrne TH. Disparities in housing status among veterans with general medical, cognitive, and behavioral health conditions. Psych Svcs 2015;66:317-20.

18. US Department of Veterans Affairs, Military Sexual Trauma Support Team. Military Sexual Trauma Factsheet. Available at https://www.mentalhealth. va.gov/docs/mst_general_factsheet.pdf. Published November 2020. Accessed November 29, 2020.

19. Tsai J, Rosenheck RA, Kasprow WJ, Kane V. Characteristics and use of services among literally homeless and unstably housed US veterans with custody of minor children. Psychiatr Serv 2015;66: 1083-90.

20. Tsai J, Rosenheck RA, Kane VR. Homeless female US veterans in a national supported housing program: comparisons of individual characteristics and outcomes with male Veterans. Psych Svcs 2014; 11:309-16.

21. O'Connell JJ. Premature mortality in homeless populations: a review of the literature. 2005. Nashville: National Health Care for the Homeless Council, Inc. http://sbdww.org/wp-content/uploads/ 2011/04/PrematureMortalityFinal.pdf. Published Dec 2005. Accessed November 28, 2020.

22. Montgomery AE, Dichter ME, Thomasson AM, Roberts CB, Byrne TH. Disparities in housing status among veterans with general medical, cognitive, and behavioral health conditions. Psychiatr Serv 2015;66:317-20.

23. Montgomery AE, Fargo JD, Byrne TH, Kane V, Culhane DP. Universal screening for homelessness and risk for homelessness in the Veterans Health Administration. Am J Public Health 2013;103: S210-S211.

24. Montgomery AE, Byrne T, Dichter M. Unique considerations for female veterans. Tsai J. (Ed.) Homelessness among U.S. Veterans: Critical Perspectives. Oxford, Oxford U.P.; 2019.

25. Department of Veterans Affairs Benefits Assistance Service. Claims for VA benefits and type of discharge. VA.gov. Available at https://www.benefits. va.gov/BENEFITS/docs/COD_Factsheet.pdf. Published March 2014. Accessed November 29, 2020.

26. Hamilton AB, Washington DL, Zuchowski JL. Gendered social roots of homelessness among women veterans. Ann Anthropol Pract 2014;37:92107. 